DOI: $10.20472 /$ AHC.2018.004.006

\title{
JERAPA SATAVETIN
}

Silpakorn University, Thailand

\section{STRATEGIC SPEECH ACTS IN PRICE NEGOTIATION}

\begin{abstract}
:
This research aimed to examine speech act strategies used in a price negotiation. The data were collected by observing and voice recording from 20 conversations between sellers and buyers in markets in Bangkok, Thailand. Searle's theory of speech acts was used as a tool to identify five illocutionary acts. Speech acts found in this study were representative, directive, commissive, expressive and declaration. The most frequent-used speech act was representative which meant sellers often used this type of speech act to inform the cost and price of products and the strengths of products. In addition, the perlocutionary act was also found in this study. In the end of conversation, the buyers decided to purchase the product with negotiated price. The sellers agreed to sell at a bargain price.
\end{abstract}

\section{Keywords:}

Speech Acts, Negotiation, Illocutionary acts 


\section{Introduction}

In communication, humans use language to convey their ideas. Therefore, language is a key tool for communication achievement. Having interaction through language can be done with different methods depending on the situation and appropriateness. Humans communicate with verbal and written language, to themselves, or with others via conversation.

Selling and buying between a seller and a buyer happens on a daily basis and verbal language is used to achieve the success. From the observation, the conversation starts with price negotiation from the buyer who applies different techniques. To link price negotiation conversation between the seller and the buyer to Speech Act theory initiated by John L. Austin, consisting of Locutionary act, Illocutionary act, and Perlocutionary act (Austin, 1962), the analysis would illustrate whether price negotiation applied those three levels or not. As a result, the researcher would like to study the language use in price negotiation for the benefits of further pragmatics research.

\section{Literature Review}

This research applied speech acts concept and analyzed the utterance with three speech acts: Locutionary act, lllocutionary act, and Perlocutionary act.

Speech acts refers to the utterance which is the smallest unit to express the speaker's meaning and intention. The analysis of language and perspective of speech act theory allows the language users to be aware of nature of language based on the diverse interaction where the colloquist and context determined the direction and outcome of interpretation. (Intachakra, 2007)

The linguists analyzed speech act in three levels to examine the meaning and intention of the speaker from the utterance. Speech act might have the same language pattern but different implication in each act. The levels of speech acts could be explained as follows.

1) Locutionary act is the language conveying the meaning consisting of three key components.

a. Sound or utterance - The speaker deliberates the thought through recognition process and conveys the meaning via the organs producing voice.

b. Utterance as a word or sentence based on language principle. It is the communication where the speaker chooses the tone, words, phrases, or sentences that are understandable to the listener. 
c. Utterance with meaning - Word contains meaning and always refers to something. Meaning of utterance means the meaning that the definition is defined formally or is known to majority people. Reference means the identification that the unclear word links to an object or person. (Intachakra, 2007)

2) Illocutionary act is an action from the utterance. All utterances contain an intention to initiate the act. It is the force to cause action. This level of speech act considers what is off the typical meaning and asserts the meaning of the speaker that mainly bases on the speaker's intention or purpose. The speaker's meaning is classified into two types (Thomas, 1995):

a. Utterance meaning or contextual meaning, which is the meaning that the interpreter shall interpret based on the context of an ongoing conversation.

b. Illocutionary force shows the actual intention of the speaker. Using a word in different situations shall convey different forces of utterance. On the other hand, diverse patterns of word may contain the same intention to communicate. However, word selection intending to communicate differently shows that the speaker gives significance to formality, politeness, and relationship with the listener differently.

Austin classified the illocutionary act consisting of verdictive, exercitive, commissive, expositive, and behabitive. However, this concept was not commonly accepted as Searle's concept (Searle, 1970) which classified illocutionary act into five acts as follows.

- Representative or Assertive speech acts: The speaker would like to give the information he/she believes it is true, which the listener may not know about, or is useful for the listener. The acts in this group are, for instance, speaking, speech, asserting, confirming, summarizing, and researching, which are positive speech acts. However, some are negative acts such as criticizing, complaining, and gossiping.

- Directive: The speaker uses the utterance to get an action from the listener such as ordering, requesting, questioning, begging, asking, suggesting, advising, and consulting.

- Commissive speech acts: It is to commit the speaker to act such as promising, vowing, gambling, proposing, soothing, assuring, intending, and threatening.

- Expressive speech acts: It expresses feelings and emotions, as well as attitude of the speaker towards the context and the listener. The speaker shall use the utterance to show what he/she likes or dislike, admires the listener or other thing that concerning with the listener only. The speaker does not want the listener to act or tell 
any important information. (Norrick, 1979) The acts in this group are greeting, welcoming, apologizing, thanking, expressing congratulations or condolence, admiring, and saying goodbye.

- Informative speech acts: It happens in the formal context where the information exchange occurs such as appointing, nominating, opening, war declaring, terminating, and sentencing.

3) Perlocutionary act is the effect of speech act from the speaker performing by the listener. That is to say there is an action after the utterance. If the listener hears the utterance and the action happens, it is the result of hearing.

\section{Research Objectives}

1. To study the three speech acts used by the seller and the buyer in price negotiation.

2. To explain illocutionary acts used by the seller and the buyer in price negotiation.

\section{Hypothesis}

2. In price negotiation situation between the seller and the buyer, the seller regularly reject at first.

3. The three speech acts: Locutionary act, Illocutionary act, and Perlocutionary act are used in price negotiation every time.

\section{Research Methodology}

The researcher processed the research on speech acts and price negotiation as the following steps.

1. Studied the paper work, documents, academic articles, books, and thesis relevant to Speech act theory and language used in commerce.

2. Investigated data source where trading was taken place and the possibility to apply the source to the research.

The researcher collected data from the language used in the various actual situations where trading and price negotiation took place. Thus, the research applied simple 
random sampling by selecting shops and markets as the samples, which were Chatuchak Market, Chatuchak Market 2, Min Buri, construction material shop in Sai Mai, and flea market in Hua Hin, Prachub Khiri Khan Province.

The situations happening in the province were chosen because the researcher would like to obtain the data of language users outside Bangkok in order to have diverse information and make the research more interesting.

The researcher chose the various types of products to study i.e. price negotiation for house furniture, consumable products, plants, clothing, and miscellaneous goods.

Because of the diversity of situation, there were various groups of buyer such as students, company employees, business owners, and general people.

The researcher acted as the customer who visited the shop and spent some time there. When there was the price negotiation of other customer occurred, the researcher recorded the conversation with the voice recorder without an awareness of the seller and buyer in order to acquire raw information and natural situation. Besides, the information was obtained from the observation and note-taking.

\section{Findings}

In the research on speech acts in price negotiation, the researcher examined the following aspects, which were locutionary act, illocutionary act, and perlocutionary act. Findings were as follows.

\section{Locutionary act}

Analysis result indicated that locutionary act was used in all situations and conversations. The speakers voiced the utterance to communicate something to the listener. The role of speaker and listener were switched between the seller and the buyer. Moreover, according to Austin's criteria of speech act for price negotiation, the conversation for price negotiation contained those criteria. That was to say the colloquists evaluated their idea through recognition process and communicate their intention via the organs producing voice (previously mentioned about the voice or utterance). Additionally, the success of the communication was from the use of tone, the understandable Thai words, phrases, or sentences between the colloquists. The utterance used always contained the meaning or referred to something. 


\section{Illocutionary act}

Illocutionary act mainly focused on the aim or purpose of the speaker. Thus, this research classified speech acts into five groups as mentioned above in order to analyze as follows.

\subsection{Representative or Assertive speech act}

The analysis on price negotiation between the buyer and the seller showed that the seller used representative or assertive speech act the most. The seller regularly provided information to the buyers as they were aware that the buyers might not know the information, or thought that the information was useful for the buyers. Most of information were price, cost of product, product properties, and the determination to not offer the discount.

- Informing the product price was considered the representative or assertive speech act. In typical selling and buying, the seller needed to inform the price to the seller for decision making. The analysis of 15 situations indicated that all of them applied representative or assertive speech act. Informing the price occurred at the very beginning of the conversation, mostly in the first sentence.

\section{Example 1}

The buyer How much does the postcard cost?

The seller It's 12 Baht.

- Mentioning the cost of product, as well as the cost per unit, was one of the strategies the seller informed the cost to the buyer. This aimed to give the actual information of product and to avoid price negotiation.

\section{Example 2}

The buyer Here, 100 Baht.

The seller Please don't negotiate. I get 5 Baht per dozen. I don't lie. I really get 5 Baht per dozen.

- Telling the properties or benefits of the product was to tell the buyer that the product had good quality and was worthy. It was the information to assure the buyer. 


\section{Example 3}

The buyer Why does it so expensive? How many do you have?

The seller There are two. It's rare and uncommon. I just got them.

These are all I have.

- Insisting not to give the discount - From the information, the seller always denied price negotiation from the buyer by insisting no discount from the first part of the conversation.

\section{Example 4}

The buyer

100 Baht please?

The seller

$$
\text { No, I can't sell at } 100 \text { Baht. }
$$

- The buyer from this group of speech act complaint that the price was too expensive and the seller should offer discount. The complaint implied the dissatisfaction with product. Besides, the buyer criticized and looked for the fault of product, and point that out in order to get discount.

\section{Example 5}

The seller No, I can't. I can give at 4,000 Baht. I don't want to carry the tree home. It's big and difficult to carry.

The buyer No, l'll give 3,500 Baht. Does it have flower? There is no flower. It's big but it has no flower. How long do I need to grow it until it bloom? Come on, 3,500 Baht please.

\subsection{Directive speech act}

The analysis showed that the seller used the word to give suggestion while the buyer asked the discount from the sellers. Moreover, there was the use of question to ask about price and possible discount. The utterance in this directive speech act expressed the attempt of the speaker to ask for the act of listener. In the situation of price negotiation, the buyer always used the speech to get discount from the sellers. Therefore, the buyer questioned about the price, which sometimes applied the assertive speech act as well. However, the suggestion of the seller would motivate the buyer to buy other products. 
- $\quad$ Questioning about the price of the buyer was found in various situations. As the use of language currently, the buyer could ask more details on price than that the sellers provided at first stage.

\section{Example 6}

The buyer How much is it?

The seller It's 80 Baht.

- Apart from questioning about price, there was the question about the product at the very first of conversation.

\section{Example 7}

The buyer How do you sell this? What is this soap? What do you call it?

The seller It's a white cleaning soap for stain removing.

- $\quad$ Directive speech act was found from the seller only in order to introduce products or suggest other options to the buyer. However, there was few found from the information, only from one situation.

Example 8

The seller Well, Auntie, you buy fertilizer 15 and another organic fertilizer to mix with. It saves half of the cost and it will help to adjust soil condition.

The buyer Will I have discount if I buy more?

\subsection{Commissive speech act}

Only few commissive speech acts were found from the information. Most of them were the promise to come back. Moreover, there was the product quality assurance from the seller by using the word "assure" in the conversation.

The sample of buyer's promising: 


\section{Example9}

The seller We meet half way, 660 Baht. If I sell 190 Baht each, 4 of them will be..., let's use the calculator, it will be 760 Baht. I give you 100 Baht discount already.

The buyer Come on, more discount is fine. l'll come back next time. 620 Baht please.

The sample of seller's assurance:

Example 10

The buyer Is it a good fabric? I bought some from the other shops, it shrank after washing.

The seller The fabric is good, no shrink. I can assure that. It's very good. Don't you take it?

This class of speech act was rarely found from the information obtained. The utterance committed the speaker to the conversation. Price negotiation was the interaction between the seller and the buyer, who were stranger to each other, in a short period of time. Therefore, the commissive speech act hardly happened between them.

\subsection{Expressive speech act}

The use of expressive speech act could be found when the seller greeted, welcomed, and thanked the buyer. It was the action from the seller only.

There was only one invitation found.

Example 11

The seller Hey, you. Come in and take a look.

The buyer Can I look at that one?

Also, the following thanks situation was found. 


\section{Example 12}

The buyer Yes, put it in the bag. 520 Baht, deal.

The seller Thank you very much. If you come to buy often, I'll give you more discount. My fabric quality is good.

\subsection{Informative speech act}

The use of utterance in informative speech act mostly happened in the formal situation. However, the information obtained was from the situation of price negotiation which was quite the informal environment. Hence, there was no informative speech act found.

\section{Perlocutionary act}

From the information, it was found that perlocutionary act in price negotiation resulted the same effect in all situations. That was to say the seller agreed to offer discount to the buyer, as the researcher limited the research scope to only the situations where the buyer was successful in price negotiation. Further, this research did not compile the nonverbal communication information. Therefore, the researcher was unable to provide the speech act regarding nonverbal communication such as nodding, smiling, or waving hand for goodbye. However, the observation implied that there was some verbal communications used. For instance, when price negotiation was successful, the buyer said "Kha" or "Krub" or "Ja", as well as smiled and nodded, which was the nonverbal communication.

\section{Discussion}

Findings illustrated that the use of speech act to convey meaning of the buyer and the seller was the use of language to express the meaning of the utterance. Illocutionary act was classified into five groups: representative or assertive speech act, directive speech act, commissive speech act, expressive speech act, and informative speech act.

Results illustrated that the buyer and the seller used representative or assertive speech act the most because the seller applied it to inform the price, cost of product, product properties or benefits, or insist not to give discount whereas the buyer used it to complain about the price, and criticize products.

Some directive speech acts were found when the buyer asked about the product price or description, and when the seller introduced the products.

Commissive and expressive speech act were found in price negotiation situation whereas the informative speech act was not presented. 
Perlocutionary act could be seen when the seller agreed with the discounted price and the buyer purchased the product.

\section{References}

Austin, J.L. 1962. How to Do Things with Words. Oxford: Clarendon Press.

Geis, M.L. 1995. Speech Acts and Conversational Interaction. Cambridge: Cambridge University Press.

Norrick, N. 1979. Expressive illocutionary acts. Journal of Pragmatics. 2:277-291.

Searle, J. 1970. Speech Acts: An Essay in the Philosophy of Language. London: Cambridge University Press.

Sommer, R. and Sommer, B. 2002. A Practical Guide to Behavioral Research: Tools and Techniques. Fifth edition. New York: Oxford University Press.

Intachakra, S. 2007. Fundamental Concepts of Pragmatics. Bangkok: Thammasat Press.

Thomas, J. 1995. Meaning in Interaction: An Introduction to Pragmatics. Malaysia: Longman. 